\title{
Strong correlation between the drag coefficient and the shape of the wind sea spectrum over a broad range of wind speeds
}

\section{$\operatorname{AUTHOR}(\mathrm{S}):$}

Takagaki, Naohisa; Komori, Satoru; Suzuki, Naoya; Iwano, Koji; Kuramoto, Takenori; Shimada, Satoshi; Kurose, Ryoichi; Takahashi, Keiko

\section{CITATION:}

Takagaki, Naohisa ... [et al]. Strong correlation between the drag coefficient and the shape of the wind sea spectrum over a broad range of wind speeds. Geophysical Research Letters 2012, 39(23): L23604.

\section{ISSUE DATE:}

2012-12

URL:

http://hdl.handle.net/2433/193710

RIGHT:

(C)2012. American Geophysical Union. 


\title{
Strong correlation between the drag coefficient and the shape of the wind sea spectrum over a broad range of wind speeds
}

\author{
Naohisa Takagaki, ${ }_{1}^{1}$ Satoru Komori, ${ }^{1}$ Naoya Suzuki, ${ }^{2}$ Koji Iwano, ${ }^{1}$ Takenori Kuramoto, ${ }^{1}$ \\ Satoshi Shimada, ${ }^{1}$ Ryoichi Kurose, ${ }^{1}$ and Keiko Takahashi ${ }^{3}$
}

Received 23 September 2012; revised 2 November 2012; accepted 2 November 2012; published 4 December 2012.

[1] Momentum transfer across the wind-driven breaking air-water interface under strong wind conditions was experimentally investigated using a high-speed wind-wave tank together with field measurements at normal wind speeds. An eddy correlation method was utilized to measure roughness length and drag coefficient from wind velocity components measured by laser Doppler and phase Doppler anemometers. As a result, a new model for the roughness length and drag coefficient was proposed for predicting momentum transfer across the sea surface under both normal and strong wind conditions using the universal relationship between energy and significant frequency of wind waves normalized by the roughness length. The model shows that the roughness length and drag coefficient are uniquely determined at all wind speeds by energy and significant frequency of wind waves, and they can be given against $U_{10}$ only from the measurements of the wave parameters and one-point mean air velocity in the logarithmic law region. Citation: Takagaki, N., S. Komori, N. Suzuki, K. Iwano, T. Kuramoto, S. Shimada, R. Kurose, and K. Takahashi (2012), Strong correlation between the drag coefficient and the shape of the wind sea spectrum over a broad range of wind speeds, Geophys. Res. Lett., 39, L23604, doi:10.1029/2012GL053988.

\section{Introduction}

[2] It is of great importance to predict the development and decay of tropical cyclones accurately in order to minimize loss of life and damage, since tropical cyclones wreak catastrophic damages to a local society with generating gale, storm surge, and heavy rain. Reliable predictions of the intensity of a tropical cyclone need accurate estimates of the momentum and heat transfer across the sea surface. One of the important issues in constructing a reliable forecast model for the decay or development of a tropical cyclone is how to accurately estimate momentum transfer rate across the airsea interface in stormy conditions. The estimate requires an accurate model of roughness length $\left(z_{0}\right)$ or drag coefficient

\footnotetext{
${ }^{1}$ Department of Mechanical Engineering and Science and Advanced Research Institute of Fluid Science and Engineering, Kyoto University, Kyoto, Japan.

${ }^{2}$ Department of Mechanical Engineering, Faculty of Science and Engineering, Kinki University, Osaka, Japan.

${ }^{3}$ Earth Simulator Center, Japan Agency for Marine-Earth Science and Technology, Yokohama, Japan.

Corresponding author: S. Komori, Department of Mechanical Engineering and Science and Advanced Research Institute of Fluid Science and Engineering, Kyoto University, Sakyo-ku, Kyoto 606-8501, Japan. (komori@mech.kyoto-u.ac.jp)

C) 2012. American Geophysical Union. All Rights Reserved. 0094-8276/12/2012GL053988
}

$\left(C_{\mathrm{D}}\right)$ against the wind speed at $z=10 \mathrm{~m}$ above the sea surface $\left(U_{10}\right)$. The sea-surface wind shear stress $(\tau)$ is expressed as:

$$
\tau=\rho u^{* 2}=\rho C_{\mathrm{D}} U_{10}^{2},
$$

where $\rho$ is the density of air and $u^{*}$ the air friction velocity. Under neutral stratification, the wind velocity profile over the rough boundary is expressed by a logarithmic profile:

$$
U(z) / u^{*}=\ln \left(z / z_{0}\right) / \kappa,
$$

where $U(z)$ is the wind speed at an elevation of $z$ and $\kappa$ $(=0.4)$ the von Karman constant. From equations (1) and (2), the drag coefficient $\left(C_{\mathrm{D}}\right)$ has an one-to-one correspondence with the roughness length $\left(z_{0}\right)$ under neutral stratification:

$$
\kappa C_{\mathrm{D}}^{-1 / 2}=\ln \left(z_{10} / z_{0}\right),
$$

where $z_{10}=10 \mathrm{~m}$.

[3] At "normal" wind speeds $\left(U_{10} \lesssim 35 \mathrm{~m} / \mathrm{s}\right)$, the roughness length is given by the well known Charnock's formula [Charnock, 1955] as $g z_{0} / u^{* 2}=\beta$, where $g$ is acceleration due to gravity and $\beta$ the so-called Charnock's constant [Charnock, 1955]. However, the value of $\beta$ is not constant among individual field measurements, possibly owing to the difficulty of directly measuring the wind shear stress of equation (1) in various sea states or to uncertainties in Charnock's formula [Charnock, 1955]. For settling this problem and developing an accurate model of momentum transfer across the air-sea interface, it is important to base a model of $z_{0}$ or $C_{\mathrm{D}}$ on the physical relationship between the wind and wind waves. In fact, instead of Charnock's formula [Charnock, 1955], some models based on the momentum transfer mechanism and the local equilibrium law for wind and wind waves [Mitsuyasu, 1968; Toba, 1972] have been proposed, using the wave age [Stewart, 1974], or the wave slope [Taylor and Yelland, 2001]. Although these models have no scientific consensus, they support the trend of $z_{0}$ or $C_{\mathrm{D}}$ increasing with $U_{10}$ in the region of normal wind speeds. In the region of extremely high wind speeds $\left(U_{10} \gtrsim 35 \mathrm{~m} / \mathrm{s}\right)$ with intensive wave breaking, the momentum transfer rate across the air-sea interface has been evaluated by simply extrapolating the values of $z_{0}$ or $C_{\mathrm{D}}$ measured under normal wind speed conditions [Grell et al., 1995; Janjic, 2001]. Thus, current models of $z_{0}$ and $C_{\mathrm{D}}$ have much uncertainty in the region of extremely high wind speeds where the momentum transfer mechanism has not been clarified and the local equilibrium law for wind and wind waves has not been confirmed.

[4] Recent field measurements [Powell et al., 2003] by means of Global Positioning System sonde in a tropical 
cyclone showed that both $z_{0}$ and $C_{\mathrm{D}}$ decrease with increasing $U_{10}$ at extremely high wind speeds, whereas previous field [Hawkins and Rubsam, 1968] and laboratory measurements [Kunishi and Imasato, 1966] suggested that $z_{0}$ and $C_{\mathrm{D}}$ increase with increasing $U_{10}$. On the other hand, recent laboratory data [Donelan et al., 2004] showed almost constant values of $z_{0}$ and $C_{\mathrm{D}}$ under strong winds of $U_{10}=$ $35 \sim 53 \mathrm{~m} / \mathrm{s}$, but their data were obtained using a momentum budget method and an eddy-correlation method by a hot-film anemometer. However, the direct measurements of the Reynolds stress by a hot-film anemometer had a problem due to a lot of dispersing droplets in air turbulent flow over intensively breaking wind waves. Thus, the trends of $z_{0}$ and $C_{\mathrm{D}}$ at extremely high wind speeds are controversial among three groups (increase, decrease, and constant with $U_{10}$ ).

[5] Therefore, we aim to investigate the momentum transfer across the breaking air-water interface under strong wind conditions by directly measuring the Reynolds stress in a high-speed wind-wave tank, and to propose a new model for $z_{0}$ and $C_{\mathrm{D}}$ applicable to a broad wind speed range including extremely high wind speeds by comparing with the field data for normal wind speeds obtained on an observation tower at sea.

\section{Experiments}

\subsection{Laboratory Experiment}

[6] The high-speed wind-wave tank with a glass test section $15.0 \mathrm{~m}$ long, $0.8 \mathrm{~m}$ wide and $1.6 \mathrm{~m}$ high, was used. Wind waves were driven in the water tank by wind speeds of $U_{10}=$ $7 \sim 68 \mathrm{~m} / \mathrm{s}$. The water-level fluctuations and wind-velocity fluctuations were measured at two fetches of $x=4.5$ and $6.5 \mathrm{~m}$ from the edge $(x=0 \mathrm{~m})$ of the entrance slope plate. The measurement position at each point in the vertical direction was defined as the vertical distance from the mean water level.

[7] A laser Doppler anemometer (Dantec LDA) was used to measure the wind-velocity fluctuations. A high-power multi-line mode argon-ion $\left(\mathrm{Ar}^{+}\right)$laser (Lexel model 95-7; $\lambda=488.0,514.5 \mathrm{~nm}$ ) with $3 \mathrm{~W}$ power was used. The $\mathrm{Ar}^{+}$ laser beam was shot through the side wall of the tank. Scattering particles with a diameter of about $1 \mu \mathrm{m}$ generated by a fog generator (Dantec F2010 Plus) were fed into the air flow over the waves. The droplets dispersed from the intensively breaking wind waves posed the LDA two problems. The first problem is the refraction of the laser beam by droplets adhered to the side glass wall of the tank. To overcome this problem, we prepared a small droplet-adherent prevention device (DAPD) and fixed it on the inside glass wall. Four orifices were installed on the device, and the four laser beams were introduced through the orifices into the test section. Compressed air was also blown at a flow volume of $85 \mathrm{~L} / \mathrm{min}$ through the orifices. Therefore, even if dispersed droplets impinged on and adhered to the orifices, the compressed air blew off droplets and created clear path for the laser beam. The other problem is the misdetection of droplets dispersed from breaking waves as tracer particles for LDA. To overcome this problem, we measured air velocity fluctuation under intensively breaking wind-wave conditions by using a phase Doppler anemometer (Dantec PDA) instead of the LDA. As the PDA enabled us to measure diameter $\left(d_{\mathrm{p}}\right)$, streamwise and vertical velocities, and the number of dispersed droplets simultaneously, we could measure the streamwise air velocity $\left(U_{\mathrm{p}}\right)$ and the product of streamwise and vertical air velocity fluctuations $\left(u_{\mathrm{p}} v_{\mathrm{p}}\right)$ by conditionally extracting the signals due to dispersed droplets of $d_{\mathrm{p}}<$ $30 \mu \mathrm{m}$. Thus, we defined the mean velocity $(U)$ and the Reynolds stress $(-u v)$ in air as the ensemble averaged values $\left(\left\langle U_{\mathrm{p}}\right\rangle\right.$ and $\left.\left\langle u_{\mathrm{p}} v_{\mathrm{p}}\right\rangle\right)$ of $U_{\mathrm{p}}$ and $u_{\mathrm{p}} v_{\mathrm{p}}$ for droplets of $d_{\mathrm{p}}<30 \mu \mathrm{m}$. For LDA measurements, the sampling frequency and sampling time were $500 \sim 5000 \mathrm{~Hz}$ and $240 \mathrm{~s}$, respectively. For the PDA measurements, the sampling frequency and sampling time were $10 \sim 500 \mathrm{~Hz}$ and $600 \mathrm{~s}$, respectively, and the measured number of detected droplets of $d_{\mathrm{p}}<30 \mu \mathrm{m}$ was up to 600 in all cases. The air friction velocity $\left(u^{*}\right)$ in equation (1) was estimated by an eddy correlation method as $u^{*}=\left(-\left\langle u_{\mathrm{p}} v_{\mathrm{p}}\right\rangle\right)^{1 / 2}$ [cf. Komori et al., 1993; Takagaki and Komori, 2007]. Here the shear stress at the interface $(\tau)$ was estimated by extrapolating the measured values of the Reynolds stress to the mean surface of $z=0 \mathrm{~m}$.

[8] The water-level fluctuation was measured using a resistance-type wave gauge (Kenek CHT4-HR60BNC). The resistance wire was installed into water, and the electric resistance changing due to the instantaneous water level was detected. The instantaneous water-level signals were transmitted directly to a digital recorder (Sony EX-UT10). The sampling frequency and sampling time were $500 \mathrm{~Hz}$ and $150 \mathrm{~s}$, respectively.

\subsection{Field Data Analysis}

[9] We analyzed the field wind data observed on an observation tower operated by Shirahama oceanographic observatory of Disaster Prevention Research Institute (DPRI) of Kyoto University, Japan. The tower was located at 33.4232 $\mathrm{N}$ and 135.1958 E in the Tanabe bay, Wakayama, Japan, as shown by a map in Shimada and Ohsawa [2011]. The distance from the tower to the nearest coast line was about $1 \mathrm{~km}$ and the water depth at the tower was $30 \mathrm{~m}$. The data periods were from 1 Jan 2005 to 31 Dec 2009. The data only for periods when the wind was blowing from the ocean were selected for eliminating the effects of land. A sonic anemometer was installed on the tower at a height of $20 \mathrm{~m}$ above the mean sea surface. Two horizontal and one vertical components of wind velocity were recorded at a sampling frequency of $10 \mathrm{~Hz}$. By applying an eddy correlation method for the wind component measurements, the air friction velocity $u^{*}$ was obtained every $10 \mathrm{~min}$. In order to select data obtained in near-neutral conditions, only the data with a bulk Richardson number of $\left|R_{\mathrm{ib}}\right|<0.02$ were used in this analysis according to Toba et al. [1990]. For an aerodynamically rough surface, we also applied a criterion for a roughness Reynolds number of $R_{\mathrm{e}}>2.3$ proposed by Toba et al. [1990]. In addition, the data contaminated by swells were discriminated by applying a criterion based on the Pierson-Moskowitz spectrum for a single peak spectrum. The discrimination method was similar to Johnson et al. [1998].

\section{Results and Discussion}

[10] Figure 1a shows the relationship between roughness length $z_{0}$ and wind-speed $U_{10}$. Here, we obtained air friction velocity directly from the Reynolds stress measured by an eddy correlation method both in the wind wave tank and at sea. At normal wind speeds of $U_{10} \lesssim 35 \mathrm{~m} / \mathrm{s}, z_{0}$ increases 
with $U_{10}$, whereas the values of $z_{0}$ approach to almost constant at extremely high wind speeds of $U_{10} \gtrsim 35 \mathrm{~m} / \mathrm{s}$. At $U_{10}$ $\lesssim 35 \mathrm{~m} / \mathrm{s}$, both our and previous field data [Mitsuyasu and Nakayama, 1969; Johnson et al., 1998] roughly follow the
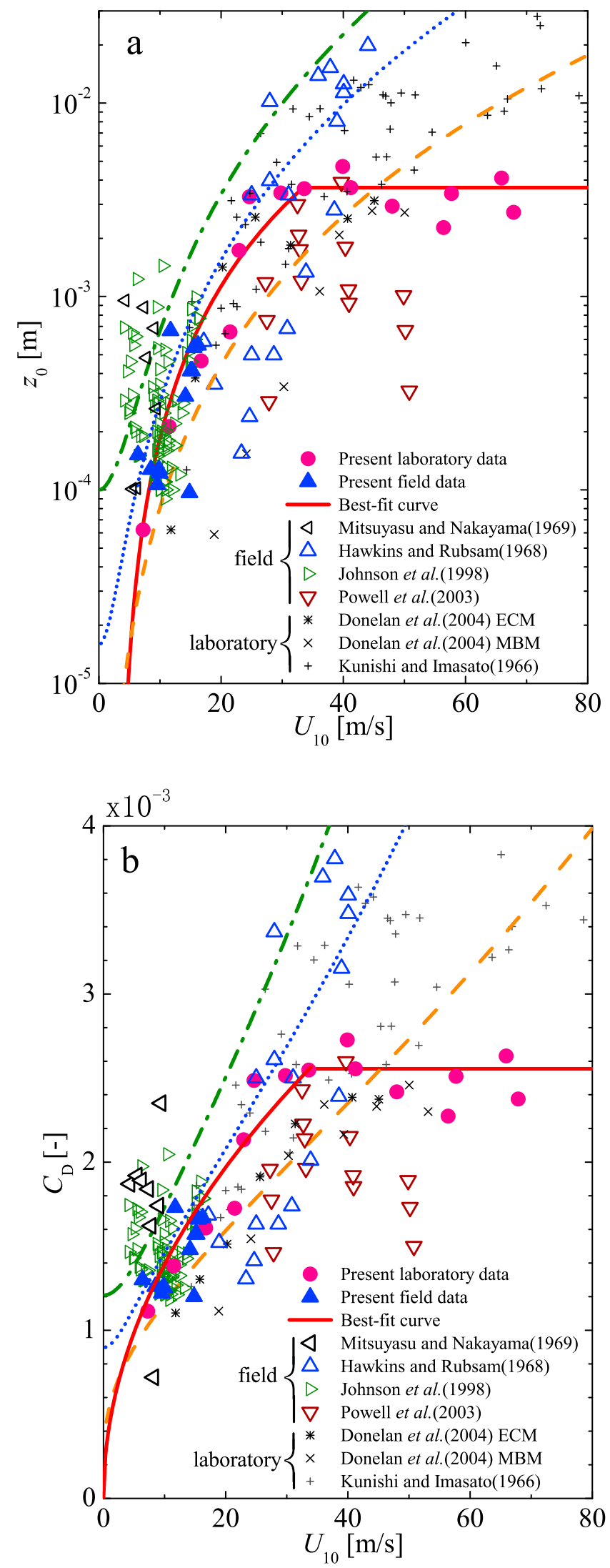

Charnock's formula [Charnock, 1955] (an orange dashed curve). Although our field data are limited to not extremely high wind speeds of $U_{10}<30 \mathrm{~m} / \mathrm{s}$ because of no stormy day, they approximate our laboratory data at normal wind speeds. At $U_{10} \gtrsim 35 \mathrm{~m} / \mathrm{s}$, among previous field [Hawkins and Rubsam, 1968; Powell et al., 2003] and laboratory [Kunishi and Imasato, 1966; Donelan et al., 2004] measurements, only laboratory measurements (cross and asterisk symbols) [Donelan et al., 2004] in a wind wave tank show a similar trend to our laboratory measurements. Although Donelan et al. [2004] succeeded in taking difficult drag measurements of intensively breaking wind waves by means of a sophisticated momentum budget method (MBM), their data (cross symbol) are limited to $U_{10}<53 \mathrm{~m} / \mathrm{s}$, and are not based on the direct measurements of the Reynolds stress. In order to verify the momentum budget method, Donelan et al. [2004] also measured the Reynold stresses using a hot-film anemometer and estimated the drag coefficients at wind speeds of $U_{10}<45 \mathrm{~m} / \mathrm{s}$ by an eddy correlation method (ECM) as shown by asterisk symbol. However, it is very difficult for a hot-film anemometry to enable us to accurately measure the Reynolds stress in an air turbulent flow with a lot of dispersed droplets over intensively breaking wind waves, since droplets impinging on the hot-film sensor adversely affect the variation of sensor temperature due to air velocity fluctuation. Other laboratory [Kunishi and Imasato, 1966] and field [Hawkins and Rubsam, 1968] measurements show the increase of $z_{0}$ with $U_{10}$ even at extremely high wind speeds, in line with Charnock's formula [Charnock, 1955] shown by an orange dashed line. On the contrary, recent field data [Powell et al., 2003] show $z_{0}$ decreasing with increasing $U_{10}$ at $U_{10}>35 \mathrm{~m} / \mathrm{s}$. However, these laboratory data [Kunishi and Imasato, 1966] and field data [Hawkins and Rubsam, 1968; Powell et al., 2003] were obtained not from the Reynolds stress directly measured by an eddy correlation method but from the friction velocity indirectly estimated by the logarithmic distribution of the wind speeds measured by a cup anemometer [Kunishi and Imasato, 1966] or Global Positioning System sonde [Powell et al., 2003], or by a rough budget between vertical and horizontal momentum fluxes in hurricane Hilda estimated from aircraft data [Hawkins and Rubsam, 1968]. Thus, the accuracy of the previous laboratory [Kunishi and Imasato, 1966; Donelan et al., 2004] and field data [Hawkins and Rubsam, 1968; Powell et al., 2003] is uncertain compared to our data based on the direct measurements of the Reynolds stress. This suggests that recent models [Grell et al., 1995; Janjic, 2001] (blue dotted and green dotted-dashed curves) used in tropical cyclone forecast models may rather overestimate $z_{0}$ at extremely high wind speeds of $U_{10}>35 \mathrm{~m} / \mathrm{s}$.

[11] Figure $1 \mathrm{~b}$ shows the distributions of $C_{\mathrm{D}}$ against $U_{10}$. $C_{\mathrm{D}}$ monotonically increases with $U_{10}$ at normal wind speeds

Figure 1. Roughness length and drag coefficient against wind speed $U_{10}$ at $z=10 \mathrm{~m}$ height. (a) Roughness length $z_{0}$. (b) Drag coefficient $C_{\mathrm{D}}$. Symbols show present and previous data taken by laboratory and field experiments. The red solid lines show the best fit curves for $z_{0}$ and $C_{\mathrm{D}}$ predicted by the present model. Dashed, dashed-dotted and dotted lines show the predictions by the models of Charnock [1955], Grell et al. [1995], and Janjic [2001], respectively. 


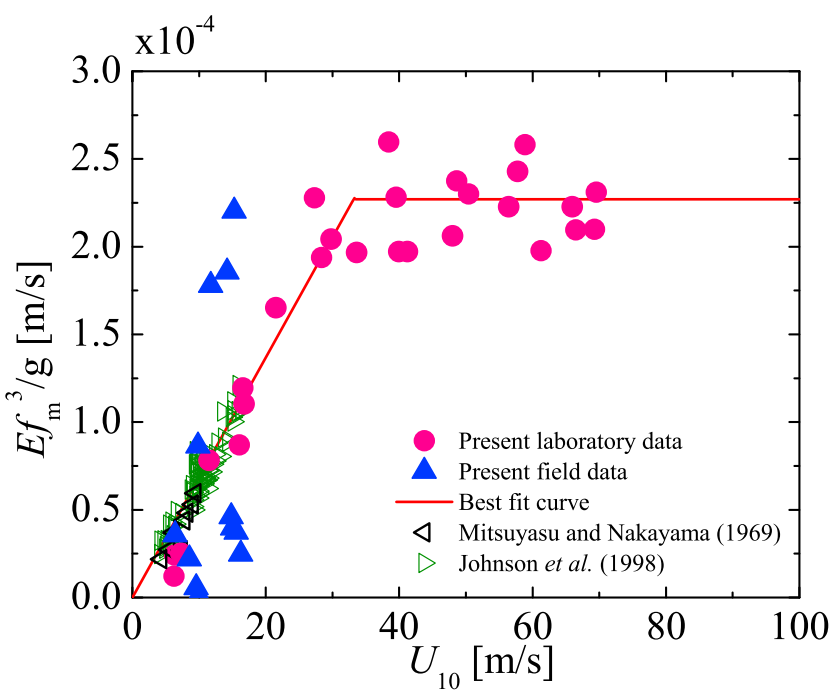

Figure 2. The relation between the property $E f_{\mathrm{m}}^{3} / g$ for representing the local equilibrium and $U_{10}$. The solid lines are the best fit curves.

of $U_{10} \lesssim 35 \mathrm{~m} / \mathrm{s}$. However, $C_{\mathrm{D}}$ is saturated at extremely high wind speeds $U_{10} \gtrsim 35 \mathrm{~m} / \mathrm{s}$, and approaches to an almost constant value $\left(2.55 \times 10^{-3}\right)$. The saturation may be attributed to the interface's flattening and slipping associated with the huge numbers of bubbles and droplets generated by intensive wave breaking. This trend of $C_{\mathrm{D}}$ is almost the same as that of $z_{0}$, because $C_{\mathrm{D}}$ has an one-to-one correspondence with $z_{0}$ as shown in equation (3).

[12] In order to develop a reliable model for $C_{\mathrm{D}}$ and $z_{0}$ applicable to real oceans from our laboratory measurements, we need to relate field and laboratory data. Therefore, we examined the local equilibrium of wind and wind waves [Mitsuyasu, 1968; Toba, 1972], which may be strongly related to the momentum transfer across the sheared wavy air-water interface. For the present laboratory/field data and previous field data [Mitsuyasu and Nakayama, 1969; Johnson et al., 1998], we estimated the energy of wind waves $(E)$ by integrating the spectrum of water level fluctuation against the frequency and defined the significant frequency of wind waves $\left(f_{\mathrm{m}}\right)$ as the peak frequency of the spectrum. As a measure of local equilibrium, we calculated $E f_{\mathrm{m}}^{3} / g$. Figure 2 shows the relationship between $E f_{\mathrm{m}}^{3} / g$ and $U_{10}$ and the red solid lines show the best fit curves for our laboratory data. Although our data are scattered, $E f_{\mathrm{m}}^{3} / g$ tends to increase linearly with $U_{10}$ at normal wind speeds of $U_{10} \lesssim 35 \mathrm{~m} / \mathrm{s}$ for all data, but our laboratory data approach to an almost constant value at extremely high wind speeds of $U_{10} \gtrsim 35 \mathrm{~m} / \mathrm{s}$, similar to $z_{0}$ and $C_{\mathrm{D}}$ (Figures 1a and $1 \mathrm{~b}$ ). Although we lack field data of $E f_{\mathrm{m}}^{3} / g$ at extremely high wind speeds, the results in Figure 2 suggest that the local equilibrium of wind and wind waves [Mitsuyasu, 1968; Toba, 1972] based on the proportional relation between $E f_{\mathrm{m}}^{3} / g$ and $U_{10}$ holds only for normal wind speeds, and collapses at extremely high wind speeds. It also highlights the need to find a new universal similarity law applicable to all wind speeds.

[13] Considering the similar distribution of $E f_{\mathrm{m}}^{3} / g$ against $U_{10}$ to that of $z_{0}$ against $U_{10}$ in Figure $1 \mathrm{a}, z_{0}$ may have strong relation to the energy $E$ and significant frequency $f_{\mathrm{m}}$ of wind waves. Therefore, we assumed the dependence of $z_{0}$ on $E$ and $f_{\mathrm{m}}$ by introducing the dimensional analysis:

$$
z_{0}=a E^{b} f_{\mathrm{m}}^{4 b-2} g^{1-2 b} .
$$

By applying the same data-analysis method as in Donelan et al. [1992] for our laboratory data, we found the optimal value of $b=2.0$ and then determined the value of $a=6.9 \times$ $10^{5}$. Figure $3 \mathrm{a}$ compares the roughness length $\left(z_{0 \mathrm{c}}\right)$ calculated by equation (4a) with the measured values $\left(z_{0 \mathrm{~m}}\right)$. It is found that the values of $a=6.9 \times 10^{5}$ and $b=2.0$ give a
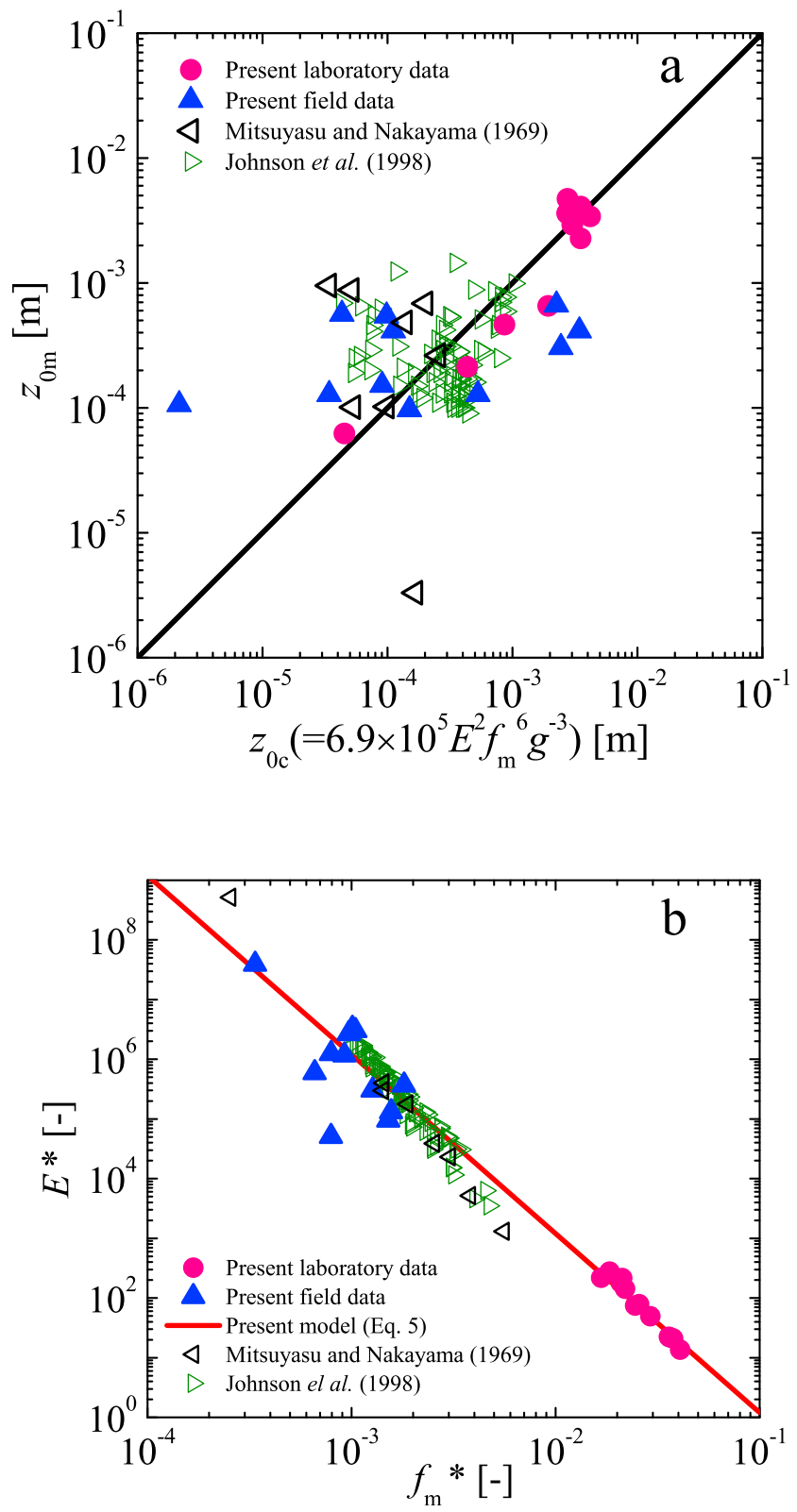

Figure 3. Dependence of roughness length $z_{0}$ on energy of wind waves $E$ and significant frequency of wind waves $f_{\mathrm{m}}$ : (a) correlation between the calculated roughness length $\left(z_{0 \mathrm{c}}\right)$ by equation (4b) and the measured roughness length $\left(z_{0 \mathrm{~m}}\right)$; (b) correlation between the energy $\left(E^{*}\right)$ and significant frequency $\left(f_{\mathrm{m}}^{*}\right)$ normalized by the measured roughness length $\left(z_{0 \mathrm{~m}}\right)$. 


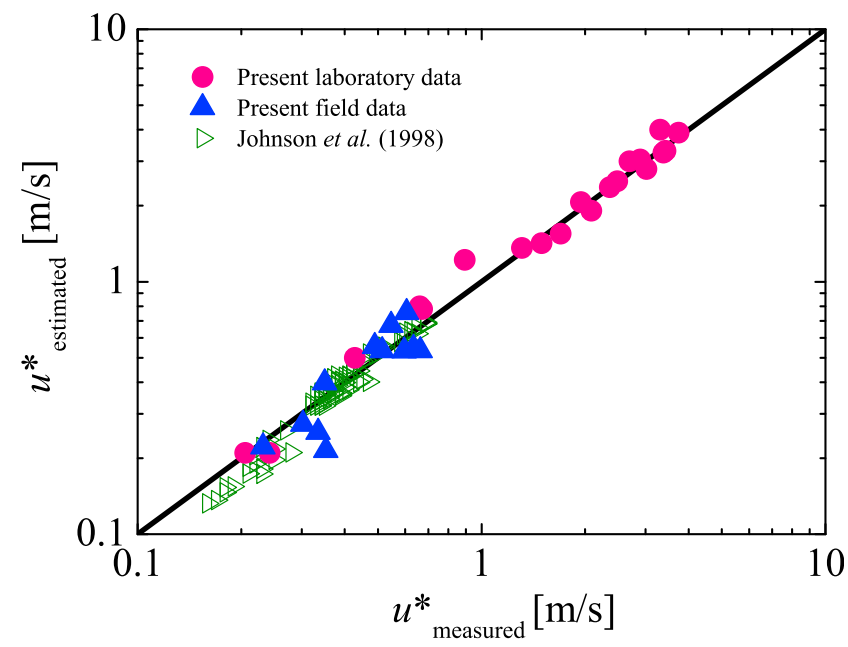

Figure 4. Relationship between measured and estimated values of air friction velocity.

good correlation for both present laboratory/field measurements and previous field measurements [Mitsuyasu and Nakayama, 1969; Johnson et al., 1998] between $z_{0 \mathrm{c}}$ and $z_{0 \mathrm{~m}}$. Therefore, equation (4a) is rewritten as

$$
z_{0}=6.9 \times 10^{5} E^{2} f_{\mathrm{m}}^{6} g^{-3} .
$$

This equation also suggests the relation between the normalized energy $E^{*}\left(=E / z_{0}^{2}\right)$ and frequency $f_{\mathrm{m}}^{*}\left(=f_{\mathrm{m}}\left(z_{0} / g\right)^{1 / 2}\right)$ as:

$$
E^{*}=\gamma f_{\mathrm{m}}^{*-3},
$$

where $\gamma=\left(6.9 \times 10^{5}\right)^{-1 / 2}=1.2 \times 10^{-3}$. In fact, the relation between $E^{*}$ and $f_{\mathrm{m}}^{*}$ normalized by the measured roughness length $\left(z_{0 \mathrm{~m}}\right)$ is well described by equation (5) as shown in Figure $3 \mathrm{~b}$. The drag coefficient $C_{\mathrm{D}}$ is also obtained from equations (3) and (5) (or (4b)) as a function of $E$ and $f_{\mathrm{m}}$ :

$$
\kappa C_{\mathrm{D}}^{-1 / 2}=\ln \left(10 \gamma^{2} g^{3} E^{-2} f_{\mathrm{m}}^{-6}\right) .
$$

These relations also mean that $z_{0}$ and $C_{\mathrm{D}}$ are uniquely determined by the shape of wind waves, because $E\left(\sim H_{\mathrm{S}}^{2} / 16\right)$ and $f_{\mathrm{m}}^{2}\left(\sim g / 2 \pi L_{\mathrm{S}}\right)$ represent the shape of wind waves, where $H_{\mathrm{S}}$ and $L_{\mathrm{S}}$ are the height and length of significant wind waves, respectively. Here, it is interesting to mention that the effect of the wave slope $(H \mathrm{~s} / L \mathrm{~s})$ is included in the universal relation of equation (5). Under the assumption of deep sea waves, we can derive the following equation from equation (5):

$$
\left(z_{0} / H_{\mathrm{S}}\right)^{1 / 2}=(2 \pi)^{-3 / 2} \gamma^{-1}\left(H_{\mathrm{S}} / L_{\mathrm{S}}\right)^{3 / 2} / 16 .
$$

This equation (7) shows that nondimensional roughness length $\left(z_{0} / H \mathrm{~s}\right)$ depends on the wave slope. When we consider that $C_{\mathrm{D}}$ is also given by equation (6) derived from equation (5), we can understand that $C_{\mathrm{D}}$ also depends on the wave slope. As a result, this means that our new similarity law of $E^{*}=\gamma f_{\mathrm{m}}^{*-3}$ in equation (5) is equivalent to equation (7) with the wave slope.

[14] On the other hand, it should be noted that our model based on the universal equation (5) enables us to determine $z_{0}$ and $C_{\mathrm{D}}$ only from the measurements of $E$ and $f_{\mathrm{m}}$ and the mean air velocity measured at an elevation in the logarithmic velocity region over the interface without using the Reynolds stress or vertical profile of the mean air velocity. That is, equation (5) gives the roughness length $z_{0}$ by equation (4b) from the measurements of the wave parameters $E$ and $f_{\mathrm{m}}$, and then $z_{0}$ and one-point mean air velocity measured at an elevation of $z$ can give the friction velocity from equation (2). When we compared the friction velocity estimated by our model with the friction velocity obtained from the Reynolds stress directly measured by the eddy-correlation method, we can see very good agreement between them as shown in Figure 4. Using the estimated friction velocity together with $C_{\mathrm{D}}$ in equation (6), we can calculate $U_{10}$ from equation (1) and can plot $z_{0}$ and $C_{\mathrm{D}}$ against $U_{10}$ as shown by red solid lines in Figures $1 \mathrm{a}$ and $1 \mathrm{~b}$. It is found that the estimated values by our model are close to our laboratory measurements. This suggests that our new model for the roughness length and drag coefficient is recommended for use in numerical models for predicting the development and decay of tropical cyclones. In order to consolidate our new similarity law in equation (5), we need more reliable field data of the energy $(E)$ and significant frequency $\left(f_{\mathrm{m}}\right)$ of wind waves together with sea-surface wind shear stress in stormy conditions. When our new similarity law is confirmed by the field data at extremely high wind speeds, our model (equations (4b) and (6)) will easily predict the roughness length and drag coefficient in oceans by using only wave height and period measured by a buoy and one-point mean air velocity measured at an elevation.

[15] We expect that our new model proposed for the roughness length and drag coefficient will be useful to understand the developing process of tropical cyclones and develop a new advanced-tropical cyclone forecast models by clarifying the effect of coexistence of wind waves and swell in an actual cyclone.

[16] Acknowledgments. This work was supported by the Ministry of Education, Science, Sports and Culture, Grant-in Aid (22246020, 23760157, and 23-1490), and the present high-speed wind-wave tank was built by the support of Core Research for Evolutional Science and Technology Program (CREST) "Advanced Model Development and Simulations for Disaster Countermeasures" of the Japan Science and Technology Agency. We gratefully acknowledge Y. Muto, Y. Baba, S. Serizawa and T. Kubo of Shirahama Oceanographic Observatory of Disaster Prevention Research Institute at Kyoto University, for providing us with the data observed at Tanabe-Nakashima oceanographic observation tower. We also thank Mark A. Donelan for his valuable suggestion for revision of our paper.

[17] The Editor thanks the two anonymous reviewers for their assistance in evaluating this paper.

\section{References}

Charnock, H. (1955), Wind stress on a water surface, Q. J. R. Meteorol. Soc., 81, 639-640, doi:10.1002/qj.49708135027.

Donelan, M. A., M. G. Skafel, H. Graber, P. Liu, D. Schwab, and S. Venkatesh (1992), On the growth rate of wind-generated waves, Atmos. Ocean, 30(3), 457-478, doi:10.1080/07055900.1992.9649449.

Donelan, M. A., B. K. Haus, N. Reul, W. J. Plant, M. Stiassnie, H. C. Graber, O. B. Brown, and E. S. Saltzman (2004), On the limiting aerodynamic roughness of the ocean in very strong winds, Geophys. Res. Lett., 31, L18306, doi:10.1029/2004GL019460.

Grell, G. A., J. Dudhia, and D. R. Stauffer (1995), A description of the fifthgeneration Penn State/NCAR Mesoscale Model (MM5), NCAR Tech. Note NCAR/TN-398+STR, Natl. Cent. for Atmos. Res., Boulder, Colo.

Hawkins, H. F., and D. T. Rubsam (1968), Hurricane Hilda, 1964 II. Structure and budgets of the hurricane on October 1, 1964, Mon. Weather Rev., 96(9), 617-636, doi:10.1175/1520-0493(1968)096<0617:HH>2.0. $\mathrm{CO} ; 2$. 
Janjic, Z. I. (2001), Nonsingular implementation the Mellor-Yamada leve 2.5 scheme in the NCEP meso model, NCEP Off. Note 437, Natl. Cent. for Environ. Predict., College Park, Md.

Johnson, H. K., J. Hojstrup, H. J. Vested, and S. E. Larsen (1998), On the dependence of sea surface roughness on wind waves, J. Phys. Oceanogr., 28, 1702-1716, doi:10.1175/1520-0485(1998)028<1702:OTDOSS $>2.0$. $\mathrm{CO} ; 2$.

Komori, S., R. Nagaosa, and Y. Murakami (1993), Turbulence structure and mass transfer across a sheared air-water interface in wind-driven turbulence, J. Fluid Mech., 249, 161-183, doi:10.1017/S0022112093001120.

Kunishi, H., and N. Imasato (1966), On the growth of wind waves by highspeed wind flume, Disaster Prev. Res. Inst. Annu., 9, 1-10.

Mitsuyasu, H. (1968), On the growth of the spectrum of wind-generated waves (I), Rep. Res. Inst. Appl. Mech., 16, 459-482.

Mitsuyasu, H., and R. Nakayama (1969), Measurements of waves and wind at Hakata Bay, Rep. Res. Inst. Appl. Mech., 33, 33-66.

Powell, M. D., P. J. Vickery, and T. A. Reinhold (2003), Reduced drag coefficient for high wind speeds in tropical cyclones, Nature, 422, 279-283, doi:10.1038/nature01481.
Shimada, S., and T. Ohsawa (2011), Accuracy and characteristics of offshore wind speeds simulated by WRF, SOLA, 7, 21-24, doi:10.2151/ sola.2011-006.

Stewart, R. W. (1974), The air-sea momentum exchange, Boundary Layer Meteorol., 6, 151-167, doi:10.1007/BF00232481.

Takagaki, N., and S. Komori (2007), Effects of rainfall on mass transfer across the air-water interface, J. Geophys. Res., 112, C06006, doi:10.1029/2006JC003752.

Taylor, P. K., and M. J. Yelland (2001), The dependence of sea surface roughness on the height and steepness of the waves, J. Phys. Oceanogr., $31, \quad 572-590$, doi:10.1175/1520-0485(2001)031<0572:TDOSSR $>2.0$. $\mathrm{CO} ; 2$.

Toba, Y. (1972), Local balance in the air-sea boundary processes I. On the growth processes of wind waves, J. Oceanogr., 28, 109-121.

Toba, Y., N. Iida, H. Kawamura, N. Ebuchi, and I. S. F. Jones (1990), Wave dependence of sea-surface wind stress, J. Phys. Oceanogr., 20, 705-721, doi:10.1175/1520-0485(1990)020>0705:WDOSSW>2.0.CO;2. 